\title{
Artificial Light at Night Reduces Daily Energy Expenditure in Breeding Great Tits (Parus major)
}

\author{
Anouk A. M. H. Welbers ${ }^{1}$, Natalie E. van Dis ${ }^{1}$, Anne M. Kolvoort ${ }^{1}$, Jenny Ouyang ${ }^{2}$, \\ Marcel E. Visser ${ }^{1}$, Kamiel Spoelstra ${ }^{1}$ and Davide M. Dominoni ${ }^{1,3 *}$ \\ ${ }^{1}$ Department of Animal Ecology, Netherlands Institute of Ecology (NIOO-KNAW), Wageningen, Netherlands, ${ }^{2}$ Department of \\ Biology, University of Nevada at Reno, Reno, NV, United States, ${ }^{3}$ Institute of Biodiversity, Animal Health and Comparative \\ Medicine, University of Glasgow, Glasgow, United Kingdom
}

OPEN ACCESS

Edited by:

Caroline Isaksson,

Lund University, Sweden

Reviewed by:

Andreas Nord,

Lund University, Sweden

Olyssa Starry,

Portland State University, United

States

*Correspondence:

Davide M. Dominon

d.dominoni@nioo.knaw.n

Specialty section:

This article was submitted to

Urban Ecology,

a section of the journal

Frontiers in Ecology and Evolution

Received: 27 February 2017 Accepted: 11 May 2017

Published: 30 May 2017

Citation:

Welbers AAMH, van Dis NE, Kolvoort AM, Ouyang J, Visser ME, Spoelstra K and Dominoni DM (2017) Artificial Light at Night Reduces Daily Energy Expenditure in Breeding Great

Tits (Parus major).

Front. Ecol. Evol. 5:55.

doi: 10.3389/fevo.2017.00055
The ecological impact of artificial light at night (ALAN) is an increasingly recognized process that accompanies expanding urbanization. Yet, we have limited knowledge on the impact of ALAN on wild species, and on the potential to mitigate any negative effects by using different light sources and colors. In birds, effects of ALAN on activity levels are reported for several species and, hence, their daily energy expenditure (DEE) may be affected. DEE is a potent mediator of life-history trade-offs and fitness and thus an important aspect to consider when examining the potential long-term ecological effects of ALAN. Previous work has suggested that birds exposed to ALAN show higher levels of provisioning and nocturnal activity, suggesting that white ALAN increases DEE. Other factors regulating DEE, such as provisioning behavior and food availability, might also respond to ALAN and thus indirectly affect DEE. We tested the hypothesis that ALAN increases DEE using an experimental setup where four previously unlit transects were illuminated with either white, green, or red LED light, or left dark as a control treatment. This setup was replicated in eight locations across the Netherlands. We measured DEE of our focal species, the great tit (Parus major), using a novel doubly labeled water technique that uses breath rather than blood samples. Contrary to our expectations, birds feeding their offspring under white and green ALAN showed lower DEE compared to birds in the control dark treatment. Differences in chick provisioning activity did not explain this result, as neither visit rates nor daily activity timing was affected by light treatment. However, food availability under white and green light was much higher compared to red light and the dark control. This difference strongly suggests that the lower DEE under white and green ALAN sites is a consequence of higher food availability in these treatments. This result shows that there can be positive, indirect effects of ALAN for breeding song birds which may balance against the negative direct effects shown in previous studies.

Keywords: ALAN, light pollution, doubly labeled water, energy expenditure, Parus major

\section{INTRODUCTION}

The alteration of natural light levels in the outdoor environment due to artificial light sources, defined as light pollution (Cinzano et al., 2000), is a globally expanding phenomenon with an estimated increase of $6 \%$ per annum (Hölker et al., 2010). It has been recently estimated that at mid-high latitudes more than $23 \%$ of land surfaces are exposed to artificial light at night (ALAN) 
(Falchi et al., 2016). In very urbanized areas like Europe, this number goes up to $88 \%$ (Falchi et al., 2016). ALAN is caused by a wide variety of light sources, such as public lighting of streets and buildings, vehicle lights, and light from advertising. Importantly, ALAN is one of the first signs of expanding urbanization, and rural land is also widely exposed to street lighting, especially in developed countries. Over the last decades, light sources, especially those of street lamps, have been undergoing a general change from narrow to broad spectrum light. A recent example is the widespread shift to LED lights (Gaston et al., 2012; Bennie et al., 2014). However, despite a recent body of studies that examined the ecological consequences of ALAN (Rich and Longcore, 2006; Migaud et al., 2007; Davies et al., 2013; Spoelstra et al., 2015), little is known about how different light spectra might affect the behavioral and physiological responses of wild species. Since LEDs color is easily modifiable, it is important to fill this research gap in order to inform policy-makers and improve future lighting strategies.

ALAN can affect several behaviors of wild animals, from orientation and navigation during dispersal and migration (Rich and Longcore, 2006; Poot et al., 2008), to daily and seasonal rhythms in behavior (Gaston et al., 2013; Robert et al., 2015; Dominoni et al., 2016), to more subtle physiological effects on stress levels, body mass and immune responses (Bedrosian et al., 2011; Ouyang et al., 2015; Raap et al., 2016a). Effects on circadian rhythms of behavior and physiology are particularly evident in a range of species, from insects to mammals (Swaddle et al., 2015). For instance, great tits (Parus major) provision their offspring at higher rates when exposed to experimental white ALAN directly at the nest box (Titulaer et al., 2012), and also show more activity at night in the lab (de Jong et al., 2016b), possibly incurring in energetic costs. In nocturnal species, such as mice and bats, ALAN is usually associated with avoidance behavior and lower activity levels at night (Stone et al., 2009; Rotics et al., 2011; Spoelstra et al., 2015). Timing of singing and sleep are also strongly affected by light pollution (Kempenaers et al., 2010; Da Silva et al., 2014; Raap et al., 2015), and such changes are suggested to have physiological consequences (Dominoni et al., 2016). For instance, sleep loss in response to ALAN is associated with reduced body mass and altered concentration of nitric oxide and haptoglobin (Raap et al., 2016b). Such physiological responses to ALAN might differ between urban and rural animals, and suggest the possibility that at least some species might adapt to and thus tolerate the presence of artificial lights. Indeed, bright nights can also offer opportunities, for example extending foraging time found for a number of diurnal species (Santos et al., 2010; Dwyer et al., 2013; Russ et al., 2015; Dominoni et al., 2016), thereby likely providing fitness benefits.

Because of the reported strong changes in activity levels associated with ALAN, we hypothesized that daily energy expenditure (DEE) might also be affected. This measure of energy metabolism is an important aspect to consider when examining the potential long-term effects of light pollution, as changes in energy metabolism are widely recognized as mediators of lifehistory traits and fitness (Wiersma et al., 2007; Hudson et al., 2013; Careau et al., 2015). Indeed, as the energy available to an individual is usually limited, it needs to be traded off between different various behavioral and physiological processes, such as feeding (Daan et al., 1996), thermoregulation (Kersten and Piersma, 2002), incubation (Cresswell et al., 2004) and territorial defense (Vehrencamp et al., 1989). The factors influencing DEE have been studied extensively in wild birds (Williams, 2012). Body mass explains most of the variation in DEE between and within species (Ricklefs et al., 1996; Nagy, 2005). Yet, environmental variables are also important regulators of energy metabolism, as temperature is usually negatively correlated with DEE (Tinbergen and Dietz, 1994; Te Marvelde et al., 2011; Regular et al., 2014) and environmental stressors are suggested to increase energy expenditure (Weimerskirch et al., 2002; Welcker et al., 2009). Food availability is also a key mediator of energy expenditure. On one hand, energy expenditure might be forced upward by lower food availability, as animals will need to work more and for longer to find food (Tinbergen and Dietz, 1994; Welcker et al., 2009). On the other hand, when resources are plentiful animals might afford to work harder and, for instance, provide more food to their offspring (Tinbergen and Verhulst, 2000; Welcker et al., 2009) or invest more energy and time in territorial defense (Vehrencamp et al., 1989), thereby increasing their DEE. In addition, a potential cost of high DEE at the cellular level is the production of reactive oxygen species, which may lead to oxidative stress (Speakman et al., 2002; Selman et al., 2008; Fletcher et al., 2013; but see also Speakman and Selman, 2011). However, higher food availability can also increase the capacity of organisms to acquire and use anti-oxidants and thus limit oxidative stress (Giordano et al., 2015). Overall, the environmental conditions in which DEE is measured need to be carefully assessed.

We tested our hypothesis using a setup in which previously unlit forest habitats were experimentally illuminated, which we extensively described in previous manuscripts (de Jong et al., 2015; Spoelstra et al., 2015). In this setup, we study the physiological and behavioral responses of rural great tits to three different spectral compositions of LED lighting (green, red and white), while using also a dark control treatment. This setup is repeated across eight different forest locations in the Netherlands. The choice of such light colors was made to cover both short (green) and long wavelengths (red), as well as the broad-spectrum white light. Because sensitivity to light in birds' photoreceptors peaks at mid-short wavelengths (Peirson et al., 2009; Hunt et al., 2014; Dominoni, 2015), we expected white and green light to be associated with stronger responses than red light and the dark treatment. Specifically, we predicted that white ALAN would increase DEE in great tits, because in previous studies we have found that white ALAN was associated with increased provisioning rate during the day (Titulaer et al., 2012), as well as with higher activity levels at night (Ouyang et al., in press), but they never directly measured energy expenditure. In addition, birds breeding under white ALAN showed higher baseline corticosterone levels compared to birds breeding in dark control areas (Ouyang et al., 2015), and this reinforced the prediction that DEE should be higher under such lighting conditions. Importantly, by measuring complementary variables we aimed at providing explanations for potential differences in DEE associated with ALAN. We collected data on the timing and 
amount of activity using transponders attached to each bird, as well as data on the abundance of caterpillars, which we define as food availability as this is the main food source of great tits nestlings (Perrins, 1991). Food availability has not been measured before in field studies that have tested the effect of artificial lights on songbirds.

\section{METHODS}

\section{Experimental Set-Up}

We illuminated previously dark natural areas with street lamps from sunset until sunrise, at eight forest sites across The Netherlands (Spoelstra et al., 2015). Lights are turned on at night at all sites since spring 2012, except for one site (Voorstonden) which had lights on since the end of April 2013. Within each site, four different transects were randomly assigned to one of four light treatments. These consists of five lampposts with white, green, or red light (Fortimo white, ClearSky green and ClearField red light, Philips, Amsterdam, The Netherlands), or wooden poles with no lamps-dark control. All three lamp types emit full spectrum light, but green lamps have an increased blue and reduced red, and red lamps have an increased red and reduced blue emission (for details on the spectral power of the light, see (Spoelstra et al., 2015). As these spectra are eventually intended for civil use, we normalized light levels to lux (intensity $7.6 \pm$ 1.2 lux, measured directly under the lamp at ground level). We placed nine nest-boxes in each transect, at different distances from the closest lamppost (median $\pm \mathrm{SD}=25 \pm 21 \mathrm{~m}$, range 1-94 m).

\section{Daily Energy Expenditure}

We measured DEE using the doubly labeled water (DLW) technique on breath samples of adult great tits, through a cavityringed laser spectrometer (L2120-i, Picarro Inc., CA, USA). This technique has been recently validated using blood samples in bird species of similar size of great tits (Mitchell et al., 2015). We caught adult great tits in nest boxes using spring traps during daytime on day 10 of chick rearing. We fitted birds with an individual aluminum ring as well as with an individual radio frequency identification (RFID) transponder, and weighed them to the nearest $0.01 \mathrm{~g}$. Within $15 \mathrm{~min}$ of capture, we used a 29 gauge $0.3-\mathrm{cm}^{3}$ syringe to inject birds intraperitoneally with 200 $\mu \mathrm{l}$ of doubly labeled water $\left(36.72 \mathrm{~g}\right.$ of $98.7 \% \mathrm{H}_{2}^{18} \mathrm{O}$ and $18.34 \mathrm{~g}$ of $99.9 \% \mathrm{D}_{2} \mathrm{O}$ ). The needle was kept parallel to the surface of the bird's belly, and then gently pushed under the skin. After the injection, we placed the birds in a cotton bag for $1 \mathrm{~h}$ to allow for equilibration of isotopes in body fluids. After this hour, we removed the bird from the bag and applied a custom-made mask to the bird's head (Figure S1). The mask has two small holes where plastic tubes were inserted. The first of these tubes was used to pump dry air $\left(<500\right.$ ppm $\left.\mathrm{H}_{2} \mathrm{O}\right)$ into the mask at a standard rate of 21 per minute, starting 5 min prior to breath measurements to ensure the spectrometer's cavity was full with dry air. The second tube was used to collect the air flowing out of the mask (consisting of dry air and bird's breath), which was then diverted into the spectrometer. The spectrometer recorded measurements of $\delta^{2} \mathrm{H}(\% \mathrm{o})$ and $\delta^{18} \mathrm{O}(\% \mathrm{o})$ approximately every $2 \mathrm{~s}$, as well as
2- and 5-min running averages. All breath samples lasted $5 \mathrm{~min}$, and we used the 2 min running average measured $30 \mathrm{~s}$ after the termination of the breath sample (Mitchell et al., 2015) in subsequent analyses of $\mathrm{CO}_{2}$ production. We recaptured birds after approximately $24 \mathrm{~h}$ (mean \pm s.d. $=23 \mathrm{~h} 49 \mathrm{~min} \pm 94 \mathrm{~min}$ ), and conducted a second breath measurement. In addition to this procedure, we obtained background isotope measurements prior to DLW injection in 25 birds, and used the averaged of such measurements for the remaining individuals. The spectrometer is prone to memory effects, that is, the isotope values obtain in one measurement can be influenced by the previous one. To reduce such effect we followed the procedure used in (Mitchell et al., 2015) and performed measurements at least 20 min apart from one another. In addition, we flushed the spectrometer cavity with ambient air in between measurements, because this has been shown to further limit memory effects (Mitchell et al., 2015).

We calculated $\mathrm{CO}_{2}$ production according to the single-pool model as in Speakman (1997). We used a respiratory quotient of 0.75 and an energy equivalence of $27.89 \mathrm{~kJ} / \mathrm{l} \mathrm{CO}_{2}$ following Speakman (1997). The water content of individuals was assumed to be $66 \%$ of body mass (Mertens, 1987).

\section{Activity Measurements: Visit Rates and Activity Timing}

On day 10, when we captured birds for the first DLW measurement, we equipped the nest box with a transponder reader (Trovan, Dorset Group BV, Aalten, The Netherlands) around the entrance hole. The reader recorded each visit that a bird made to the nest. We used recordings collected on day 11, from the first to the last visit of this day.

Non-independent RFID readings caused by birds residing in the nest box entrance were excluded by removing readings with an interval shorter than $17 \mathrm{~s}$. This "cutoff point" was identified by a peak in the frequency histogram of consecutive recording intervals. We validated this method using nest box visit data from pied flycatchers (Ficedula hypoleuca) breeding in the same region. After excluding these data, we calculated the total number of visits per hour per bird and used this variable in all our models. We excluded the first and last hour of recording for each day as these were usually truncated and therefore the calculation of hourly means would have been biased. As the amount of data used per bird per day is clearly affected by lengthening of days during the spring progression, we corrected for this potential bias by including Julian date as explanatory variable in all our models (see below).

We also used the transponder data to calculate the time of onset and offset of activity, by locating the earliest and latest visit time of the adults within a day. We expressed these times relative to the objective (natural) sunrise, sunset and day length time, which we obtained from the US Geological Survey website (http://aa.usno.navy.mil/data/docs/RS_OneYear.php). We calculated the duration of the activity phase as the difference between the offset and onset.

\section{Caterpillar Availability}

We assessed caterpillar availability using frass nets, where the biomass of caterpillar above the net can be calculated from 
the droppings ("frass") of the caterpillars (Tinbergen and Dietz, 1994), in 3 consecutive years, from 2014 to 2016 . Frass nets $(0.5$ $\times 0.5 \mathrm{~m}$ ) were placed at $1 \mathrm{~m}$ distance from the trunk of the oak closest to the lamppost (Visser et al., 2006). We placed one net in each of the four transects of the site with the highest caterpillar abundance, Voorstonden, as this is the only site consisting of primarily deciduous trees (Spoelstra et al., 2015), while the other sites harbor mostly evergreen species (spruce and pines). In 2016, we also placed nets in all other seven sites under birch trees when these were available, and otherwise under pine trees. Since the total frass collected in these additional sites was extremely low (most samples contained no frass, Figure S2), we decided to use caterpillar biomass data exclusively from Voorstonden for statistical analyses.

Over the breeding period (2014: March 24 to May 22; 2015: April 4 to June 8; 2016: April 18 to June 12), frass nets were emptied on average every 4 days (range 2-14 days) with more regular sampling in the middle of the breeding season (every 2-5 days). Any large debris was removed before collecting. On average, 70 samples were collected over the course of the breeding season each year (range 52-84), with an equal number of measurements for each of the transects (mean $=17$ samples per transect per year). In 2015 and 2016, samples were dried at $60^{\circ} \mathrm{C}$ for $24 \mathrm{~h}$, sorted and weighed following (Visser et al., 2006). In 2014, sorting was performed manually with the use of a microscope. From the dry weights, caterpillar biomass was estimated using the formula by Tinbergen and Dietz (1994), to obtain caterpillar biomass in grams per day per square meter.

\section{Statistical Analyses}

We ran all statistical analyses using the software $R$ ( $R$ Development Core Team, 2015). Our basic approach was to use linear mixed models (LMMs) with a Gaussian error structure for all our analyses, using the lme4 package (Bates et al., 2015). We always included site as a random factor, as well as nest box, the latter to correct for non-independent measurements conducted on paired adults that bred in the same box. We also included ID as random factor when repeated measures were conducted on the same animal (for the RFID data). We checked the model fit by inspecting graphs of residuals.

We conducted model selection based on likelihood ratio tests using procedures implemented in the $\mathrm{R}$ package lmerTest (Kuznetsova et al., 2016). We started with the most complex model with all biologically relevant fixed effects and then sequentially removed non-significant effects until the best model was found. When treatment had a significant effect on the response variable, we tested for differences between light colors with a Tukey post-hoc test implemented in the $\mathrm{R}$ package multcomp (Hothorn et al., 2008). When the interaction treatment*distance was significant, we conducted independent LMMs for each of the four treatments separately.

We ran five main models with the following as response variables: (1) DEE, (2) Visit rates per hour (RFID data), (3) Time of first morning visit activity, (4) Time of last evening visit, (5) Active day length (difference between first and last visits, all from RFID data). In addition, we ran two LMMs to relate individual DEE values (response variable) to visit rates. In all these models we included treatment, distance to closest lamppost, sex, mass, Julian date and the interaction between treatment and distance as fixed effects. In the models for DEE and visit rates, we also included brood size as a fixed effect.

To analyze caterpillar abundance data, we extracted peak height (maximum estimated caterpillar biomass in grams per day) and peak date (date at which maximum was measured) for each tree sampled (Visser et al., 2006). We used these two as response variables in two linear models with treatment and year as fixed effects, as well as their interaction. We log-transformed peak height to meet normality assumptions. We then performed Tukey post-hoc tests (see above) to test for significant differences between years and treatments.

\section{RESULTS}

\section{Daily Energy Expenditure}

We obtained DEE measurements from 55 birds $(N=34$ females and 21 males; $\mathrm{N}$ dark $=18$, green $=13$, red $=14$, white $=$ 10). DEE levels were significantly affected by the light treatment $\left(\chi^{2}=10.53, P=0.015\right)$. Post-hoc tests (treatment-specific linear regressions) showed that the birds in the dark treatment had significantly higher DEE levels compared to birds in both the white and green treatment $(z=-2.73, P=0.032$, and $z=$ $-2.03, P=0.018$, respectively, Figure 1 and Table S1). All other pairwise comparisons between different light treatments were not significant $(P>0.4$ in all cases). In addition, brood size had a marginally non-significant and positive effect on $\operatorname{DEE}\left(\chi^{2}=5.34\right.$, $P=0.060)$ : that is, parents spent more energy when they had to feed a higher number of nestlings. No other variables were significantly associated with DEE (Table S1).

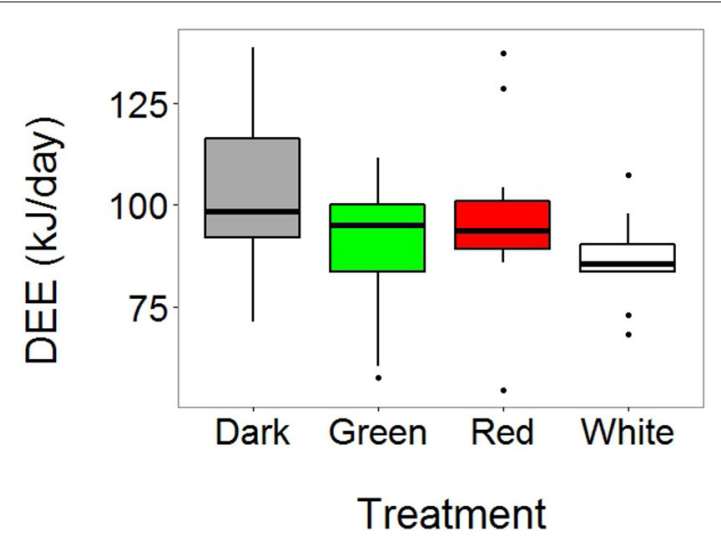

FIGURE 1 | Light at night affects daily energy expenditure (DEE) in free-living adult great tits. Horizontal, black line in boxplots represents median DEE $(\mathrm{N}$ dark $=18$, green $=13$, red $=14$, white $=10)$. Birds were captured at their nest box on day 10 of the chick-rearing period, and injected with doubly labeled water (DLW). We then waited for $1 \mathrm{~h}$ to allow equilibration of DLW in body fluids, and subsequently measured isotope concentrations in breath during a 5 min period using a custom-made mask attached to a cavity-ringed laser spectrometer. Birds were released and after approximately $24 \mathrm{~h}$ they were recaptured to obtain a new breath measurement. DEE was calculated after (Speakman, 1997). Birds breeding under white and green light at night spent significantly less energy compared to the birds in the dark treatment. 


\section{Activity Measurements: Visit Rates and Activity Timing}

We obtained RFID data from 70 individuals $(N=37$ females and 33 males) from 43 nests $($ dark $=14$, green $=10$, red $=11$, white $=$ 8). Our final model showed a significant effect of the interaction between treatment and distance to the closest lamppost on the number of visits per hour $\left(\chi^{2}=11.54, P=0.009\right.$, Figure 2 and Table S2). Post-hoc tests showed that in the green treatment there was a negative relationship between the distance to the closest lamppost and the number of visits to the nest $(t=-2.39, P=$ $0.037)$. Conversely, such a relationship was absent in all other treatments $(P>0.28$ in all cases, Figure 2$)$. In addition, the full model showed highly significant, negative effects of both Julian date $\left(\chi^{2}=15.84, P<0.001\right)$ and time of day on the number

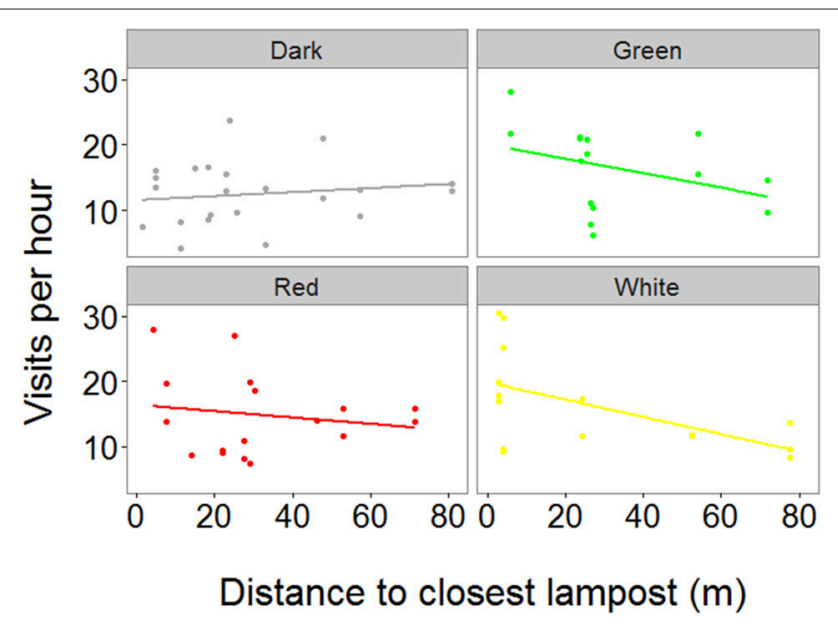

FIGURE 2 | Relationship between the distance to the closest lamppost and visit rates of parent great tits. We found a significant interaction between treatment and distance to the closest lamppost on visit rates, with the birds in the green treatment visiting their nest box more when breeding closer to the light source. X-axis depicts distance of a single nest box (dots) to the closest lamppost. Y-axis depicts the average number of visits per hour that one individual bird made to its nest box. The measurements were conducted during the chick rearing period, when chicks were 10-11 days old, using RFID transponders attached to each individual bird ( $\mathrm{N}$ dark $=22$, green $=15$, red $=$ 18 , white $=15$ ) of visits per hour $\left(\chi^{2}=101.29, P<0.001\right)$, meaning that birds visited the nest less often both late in the season as well as late in the day. In addition, there was a positive although weak effect of brood size on visit rate $\left(\chi^{2}=4.34, \mathrm{P}=0.043\right)$. There was no significant difference in visit rates between males and females $\left(\chi^{2}\right.$ $=0.60, \mathrm{P}=0.44$ ).

First and last visit to the nest box, as well as the duration of the active day, were not affected by light treatment $\left(\chi^{2}=2.29, \mathrm{P}=\right.$ $0.514 ; \chi^{2}=4.30, P=0.231 ; \chi^{2}=1.38, P=0.711$ respectively, Figure 3 and Table S3). The duration of the active day was higher in females than males (females: mean \pm sd $=15 \mathrm{~h} 2 \mathrm{~min} \pm 24$ min; males: 14 h $26 \mathrm{~min} \pm 48 \mathrm{~min} ; \chi^{2}=13.75, P<0.001$ ). This was due to a sex difference in both the time of the last visit (females: mean $\pm \mathrm{sd}=25 \mathrm{~min} \pm 30$ min before sunset; males: $53 \mathrm{~min} \pm 31 \mathrm{~min}$ before sunset; $\left.\chi^{2}=15.19, P<0.001\right)$ and first visit to the nest box (females mean $\pm \mathrm{s} . \mathrm{d}=-1.32 \mathrm{~min} \pm 30 \mathrm{~min}$ before sunrise vs. males $6.58 \pm 35 \mathrm{~min}$ after sunrise; $\chi^{2}=7.96$, $\mathrm{P}=0.005)$.

We then correlated the RFID data to the DEE data, and found a significant interaction between treatment and visit rates in predicting DEE $\left(\chi^{2}=12.49, \mathrm{P}=0.006\right.$, and Figure 4$)$. Indeed, independent LMMs run for each treatment showed that visit rates significantly predicted DEE in the dark and red treatment $(t=$ 2.2, $P=0.027$ and $t=7.9, P<0.001$, respectively, Figure 4$)$, but not in the green and white treatment $(t=1.3, P=0.194$ and $t=$ $1.4, P=0.195$, respectively, Figure 4).

\section{Caterpillar Availability}

Peak height in caterpillar abundance, expressed as the maximum estimated caterpillar biomass in grams per day, was significantly affected by treatment $\left[F_{(3,13)}=11.49, P=0.001\right.$, Figure 5, Table S5]. Post-hoc tests revealed that abundance was 7 times higher in the green treatment and 6 times higher in white treatment compared to the dark treatment (green-dark: backtransformed estimate $=7.05, P=0.002$; white-dark: backtransformed estimate $=6.11, P=0.004)$. Moreover, both green and white treatments differed from the red treatment, although the differences were smaller, with a 3 times higher caterpillar abundance peak in the green and the white compared to the red (red-green: estimate $=0.30, P=0.044$; white-red: estimate $=2.91, P=0.079)$. There were no differences between years in
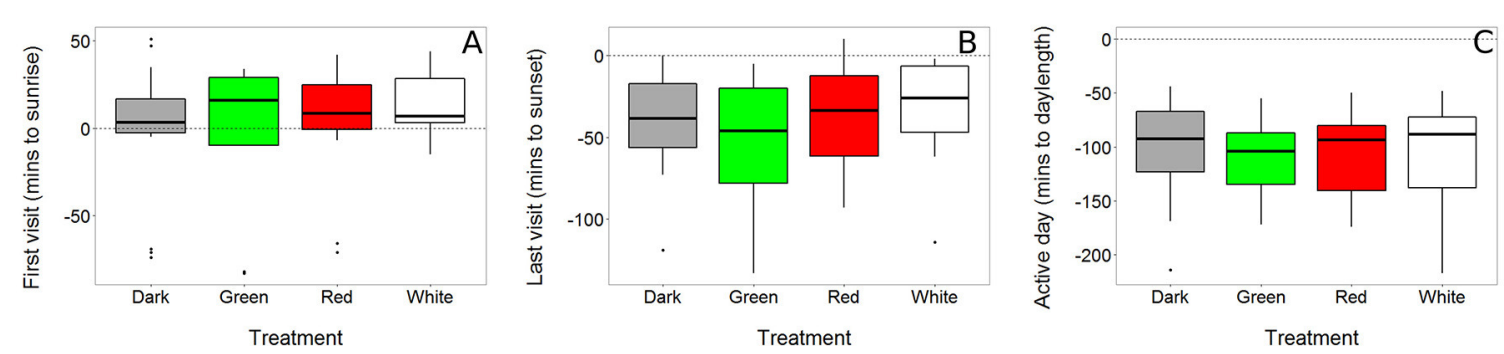

FIGURE 3 | Timing of daily activity was not affected by light at night. First (A) and last visit (B) of a bird to its nest box were recorded using RFID transponder data (see Figure 2). The time that a bird was active during the day ("active day," C), was calculated as the difference between the last and first visit of a day. All data are expressed relative to the natural sunrise, sunset and day length, which are depicted in the graphs as dashed horizontal lines crossing zero ( $\mathrm{N}$ dark $=22$, green $=$ 15 , red $=18$, white $=15)$. 
peak height $\left[F_{(2,12)}=2.6, P=0.123\right.$, Figure 5, Table S5]. Light treatment did not have an effect on peak date $\left[F_{(3,13)}=1.1, P\right.$ $=0.39$, Figure 5, Table S5]. Although in 2015 and 2016 peak date was 7 and 8 days later than in 2014, respectively, we only detected a marginal, non-significant effect of year in our models $\left[F_{(2,12)}=\right.$ 3.1, $P=0.087$, Table S5].

Given the strong differences in peak height of caterpillar abundance between the green/white sites and the dark sites, we suspected that these could be associated with the lower

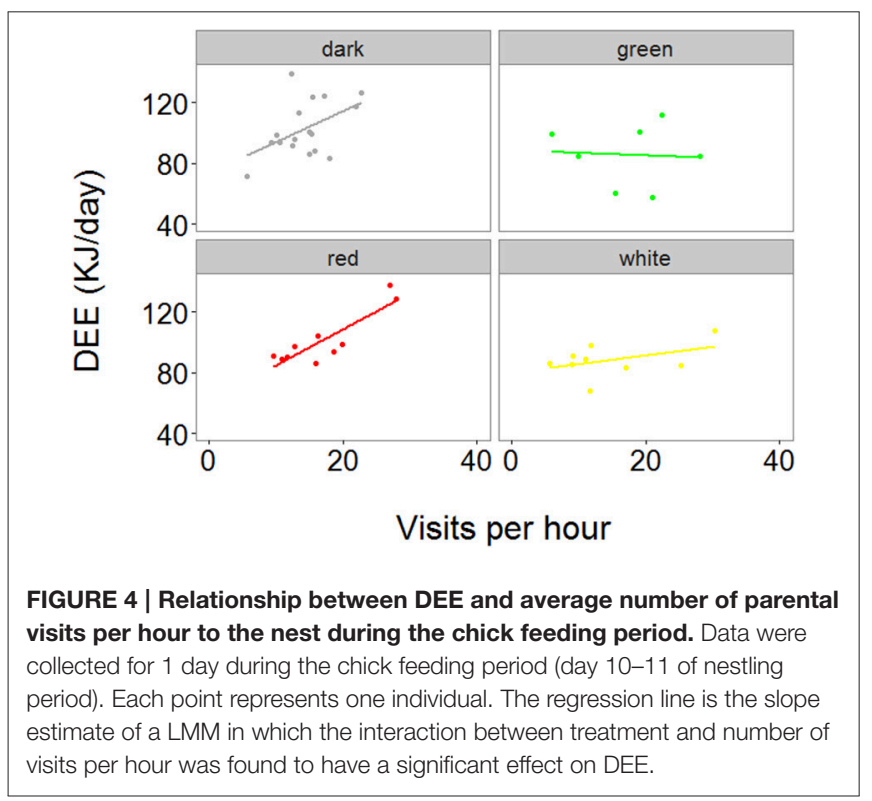

DEE found in the birds breeding under white and green light compared to the dark control. To test this hypothesis, we created two additional datasets for the DEE measurements with (1) only data from the caterpillar-richest site, Voorstonden (see Spoelstra et al., 2015) for details on this site), and (2) all sites excluding Voorstonden. The effect of treatment on DEE was only present in the dataset with only Voorstonden $(N=24, P=0.026, F=$ 3.8). Post-hoc tests showed a significantly lower DEE in the green compared to the dark treatment $(t=-3.20, P=0.021)$, and a marginally non-significant lower DEE in the white compared to the dark treatment $(t=-2.50, P=0.089)$. Conversely, there was no treatment effect on DEE in the dataset with all sites except Voorstonden $\left(N=31, P=0.61, \chi^{2}=1.82\right)$.

\section{DISCUSSION}

Our study revealed an effect of artificial light at night (ALAN) on the energy expenditure of breeding wild great tits. Birds exposed to either green or white nocturnal light had lower DEE levels compared to the control dark group. Previous studies suggested that adult songbirds exposed to white ALAN showed higher provisioning rates during the day (Titulaer et al., 2012), as well as higher restlessness at night (Dominoni et al., 2013; de Jong et al., 2016a; Ouyang et al., in press), although energy consumption was never directly measured. Thus, we predicted DEE to be higher in the white ALAN group compared to all other treatments. This was clearly not the case. One option why restlessness at night does not lead to a higher DEE is that it is not energetically costly, such as foraging or flying, leaving DEE unaffected. Relative to this, it is important to note that locomotor activity may not be the main

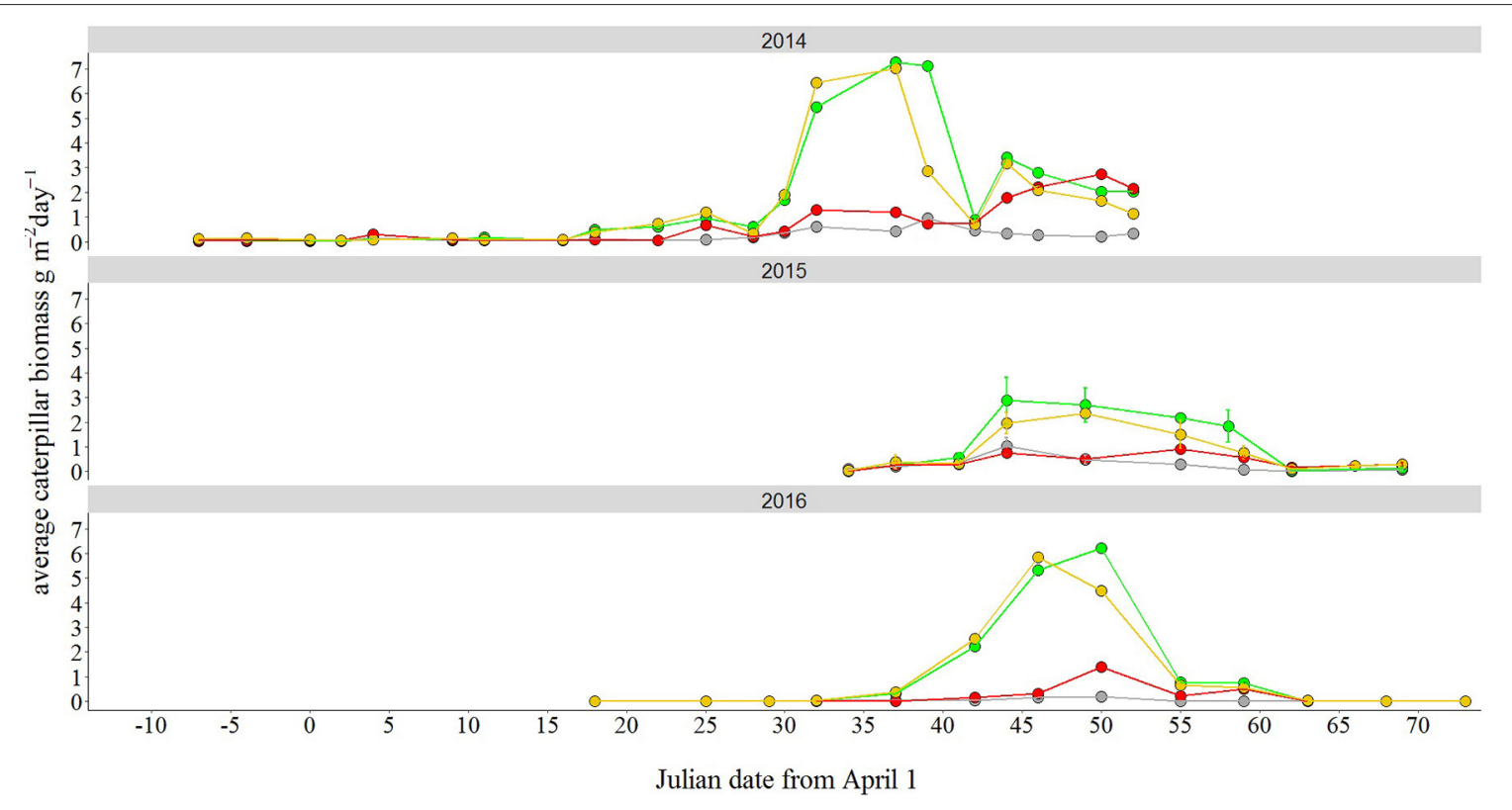

FIGURE 5 | Effect of light at night treatment on caterpillar abundance. Caterpillar biomass was much higher in both the green and white light treatment compared to the dark one. Biomass (in $\mathrm{g} / \mathrm{m}^{2}$ per day) was estimated from caterpillar frass, by placing one frass net in each light transect for only the richest caterpillar biomass site, Voorstonden. Points represent mean values. In 2015 we sampled two trees per treatment, hence we use error bars (SEM). The white light treatment is here depicted in yellow for visualization purposes. 
driver of day/night differences in DEE, as birds show a circadian rhythm in energy metabolism that is independent of activity (Pohl, 1977). In addition, higher nocturnal restlessness could simply be attributed to the disruptive effect of white ALAN on sleep (Raap et al., 2015), rather than to an increase in locomotor activity. Some studies in humans and rodents have suggested that sleep disruption may increase DEE (Markwald et al., 2013), but others have found the opposite effect (Benedict et al., 2011). We suggest that other mechanisms may play a far bigger role in explaining our results.

Our data suggest that the increased food availability in the white and green ALAN treatments could have partly mediated the lower DEE levels found in these treatments. Food availability has never been considered in light pollution studies on Parid species. We have measured the abundance of caterpillars during the last three springs, and in all years the green and white ALAN treatments had a considerably higher peak in caterpillar biomass compared to the dark and red treatments, although only in the caterpillar-rich site, Voorstonden (see below for a more thorough discussion on this point). It is therefore conceivable that at this site birds breeding under green and white ALAN had to work less to search and obtain caterpillars for their offspring, thereby spending less energy than birds in dark areas. Indeed, previous research shows a negative relationship between caterpillar abundance and energy expenditure of wild great tits (Tinbergen and Dietz, 1994). In addition, when brood size is manipulated experimentally in great tits, DEE is lower in smaller than larger broods, suggesting that when food availability is relatively large (because parents have to feed less offspring than they planned for), a decrease in DEE is observed. The higher abundance of caterpillars under white and green light is not surprising, as mid and short wavelengths are known to attract more flying insects, and especially Lepidoptera species, than long wavelengths such as red light (van Langevelde et al., 2011). This is also true at our sites (Spoelstra et al in revision). Different light spectra could thus alter the balance between costs and benefits of light pollution for predator birds and their insect preys, an hypothesis that has already been suggested for other types of species interactions (Davies et al., 2013; Sanders et al., 2015).

Obviously, without a direct manipulation of food availability our conclusion that DEE is reduced due to an indirect effect of ALAN on food availability is mostly speculative, but at least two other results support it. First, DEE was lower in the birds in the green and, marginally significant, white ALAN treatments in the site with the highest amount of caterpillar biomass, Voorstonden. This site has the highest concentration of native deciduous trees (oaks and birches) which are known to be the preferred host species of Lepidoptera larvae that Parid species feed on (Visser et al., 2006; Tallamy and Shropshire, 2009; Burghardt et al., 2010). Conversely, the other seven sites are mostly evergreen forests and harbor very little caterpillar biomass, which does not differ between light treatments (Figure S2). When we used DEE data from these sites only, there was no longer a significant difference in DEE between the four treatments. It would be interesting to analyze the diet of great tits in these caterpillarpoor sites, to test whether the lack of caterpillars is compensated with other food sources, as well to sample more deciduous sites in order to avoid pseudo-replication. It could also be possible that the low caterpillar abundance at these evergreen sites precluded accurate measurements of any treatment effect, and/or the flora in some habitats is more responsive to the light stimulation than in others. Second, the relationship between the visit rates and the distance of a nest box to the closest lamppost depended on light treatment. In the green treatment, birds visited the nest box more often when breeding close to the lamppost than further away, while the opposite was found in the dark areas. Sampling caterpillar abundance with increasing distance to the lampposts might help elucidating whether caterpillar biomass varies as a function of the distance to the lamppost.

Interestingly, the relationship between DEE and visit rates depended on light color. While DEE was significantly related to visit rates in the dark and red ALAN treatments, we found no correlation between these two variables in the green and white light. It is well known that visit rate of parent birds during the chick-rearing period does not always relate to DEE, as many other behavioral and physiological factors contribute to energy expenditure aside from provisioning (Tinbergen and Dietz, 1994; Verhulst and Tinbergen, 1997; Williams, 2012). Thus, our results are not contradictory with the existing literature, yet they are very intriguing. It appears that short (green) as well as broad (white) spectrum illumination alters the relationship between work rate and DEE. Thus, there is a striking fit between the results for caterpillar frass, DEE and light treatments. This strongly suggests that the higher food availability found under white and green ALAN might alter foraging behavior and ultimately explain the differences in DEE. Although absolute provisioning rates do not vary between light treatments, birds in the white and green light sites may have to work less to find food for their offspring, disrupting the relationship between DEE and visit rates found under natural dark nights. It has been recently highlighted that environmental as well as endogenous factors can alter the relationship between behavior and physiology (Killen et al., 2013). Our results point in this direction, as we show that DEE and provisioning behavior are not always correlated, but this relationship depends on the environment where birds breed, which in turn is affected by the experimental light source via changes in food availability. Such indirect effects of ALAN have rarely been taken into consideration, but they are likely to be more widespread than currently appreciated.

Activity times of the birds did not differ between treatments. Thus, it is unlikely that differences in active day length could have explained the (observed) lower DEE levels in the green and white treatments. Songbirds are known to extend their activity into night when exposed to light pollution, both in the evening but especially in the morning (Da Silva et al., 2014; Dominoni et al., 2014; Russ et al., 2015; de Jong et al., 2016a), which suggest that ALAN might increase DEE through the lengthening of the active day. However, our results show the opposite trend, with birds in the dark treatments visiting their nest box on average earlier in the morning, and later in the evening, compared to the birds in the light treatments. 
Females had a longer active day than males, and this is not surprising as females usually stay in the nest box at night during for most of the breeding period. Therefore, unless males visit the nest box before the female awakes (which is unlikely at least in our own experience studying this species), the female will be the first bird to trigger the transponder reader in the morning (and the last in the evening). In addition, a recent study conducted at our sites showed that onset of dawn song in male birds did not vary between the different light treatments in several different species, including the great tit (Da Silva et al., 2017). This result may be related to our use of relatively low, realistic light intensities for countryside roads in addition to the difference with non-experimental situations where light is correlated with other disturbances (see Spoelstra and Visser, 2013). This might also hint to the fact that any behavioral or physiological changes that we observed between our treatments are unlikely to be a consequence of a direct effect of light exposure, but rather of indirect effects such as changes in food availability.

Although we used experimentally illuminated previously dark habitats, a limitation of our study, and more in general of our experimental set-up, is that we are unable to control for non-random settlement patterns of birds in the different light treatments. Birds with different metabolic rates, personality traits, sensitivity to light, or additional physiological/behavioral characteristics might have settled in the different areas. Thus, our results might be a consequence of such non-random settlements rather than an effect of light on DEE, either direct or indirect. Although this explanation is unlikely (see additional discussion in de Jong et al., 2015), these results have important consequences for our understanding of the ecological impacts of ALAN. They suggest that when artificial illumination is localized in small rural and forest locations, its indirect effect of increased insect availability may offset the negative direct effects on stress and sleep disruption previously reported. However, in more densely urbanized areas with pervasive presence of light pollution and sparse, exotic vegetation, the positive effects of light pollution on food availability that our study suggest might not be present. Indeed, the quantity and quality of caterpillars in urban areas is usually low (Isaksson and Andersson, 2007), and in a previous study DEE was found to be higher in urban compared to rural great tits, although no information was provided on food availability nor on exposure to light (Hinsley et al., 2008). In addition, urban-adapted animals might have very well developed tolerance to the presence of artificial lights (Dominoni et al., 2013). Future studies should focus on experimentally testing the interaction between ALAN, food availability and the behavioral as well as physiological differences between urban and rural animals in response to light pollution.

Taken together with previous research in this field, our results suggest that white and green lights likely have the greatest effect on great tits' behavior and ecology, through both direct and indirect effects. Conversely, longer wavelengths leaning toward the red spectrum seem to induce similar behavioral and physiological responses to living in darkness (but see de Jong, 2016). Such results are comparable to observations on mammals, in particular mice and bats (Spoelstra et al., 2015), and point to red light being a useful opportunity to minimize the impact of light pollution on wildlife. Such finding is not surprising, as most photoreceptors in mammals and birds have peak sensitivity around mid and short wavelengths (Peirson et al., 2009; Hunt et al., 2014). However, more research is needed, especially to understand how generalizable these results are to other avian and mammalian species, but also to other organisms that live in light polluted environments.

\section{ETHICS STATEMENTS}

This study was carried out in accordance with the recommendations of the Animal Experimentation Committee (DEC), KNAW, with the protocol number "NIOO 14.05 addendum2."

\section{AUTHOR CONTRIBUTIONS}

AW, NV, MV, KS, and DD designed the study. AW, NV, AK, JO, and DD collected the data. AW, NV, and DD analyzed the data. AW and DD wrote the paper. All authors read, commented on and approved the final version of the manuscript.

\section{FUNDING}

The setup and maintenance of the experimental facilities of "Licht Op Natuur" is financed by the Dutch Technology Foundation STW, part of the Netherlands Organization for Scientific Research (NWO). The project is supported by Philips and the Nederlandse Aardolie Maatschappij (NAM). We thank Staatsbosbeheer, Natuurmonumenten, the Dutch Ministry of Defence, Het Drentse Landschap and the municipality of Ede for the use of their terrain. This specific study was funded by the NWO grant "Ageing in the light" (260-25310) to DD and MV.

\section{ACKNOWLEDGMENTS}

We thank Staatsbosbeheer, Natuurmonumenten, the Dutch Ministry of Defence and Het Drentse Landschap for allowing us to illuminate natural habitat and to work in their terrain. We further thank Lucia Salis and Bart van Lith for their help during field work. Last, we thank Chris Guglielmo and Keith Hobson for their useful suggestions on the laser spectrometer, and Hans Zweers for his help to install the Picarro spectrometer.

\section{SUPPLEMENTARY MATERIAL}

The Supplementary Material for this article can be found online at: http://journal.frontiersin.org/article/10.3389/fevo. 2017.00055/full\#supplementary-material 


\section{REFERENCES}

Bates, D., Maechler, M., Bolker, B., and Walker, S. (2015). Fitting linear mixedeffects models using lme4. J. Stat. Softw. 67, 1-48. doi: 10.18637/jss.v067.i01

Bedrosian, T. A., Fonken, L. K., Walton, J. C., and Nelson, R. J. (2011). Chronic exposure to dim light at night suppresses immune responses in Siberian hamsters. Biol. Lett. 7, 468-471. doi: 10.1098/rsbl.2010.1108

Benedict, C., Hallschmid, M., Lassen, A., Mahnke, C., Schultes, B., Schiöth, H. B., et al. (2011). Acute sleep deprivation reduces energy expenditure in healthy men. Am. J. Clin. Nutr. 93, 1229-1236. doi: 10.3945/ajcn.110.006460

Bennie, J., Davies, T. W., Duffy, J. P., Inger, R., and Gaston, K. J. (2014). Contrasting trends in light pollution across Europe based on satellite observed night time lights. Sci. Rep. 4, 1-6. doi: 10.1038/srep03789

Burghardt, K. T., Tallamy, D. W., Philips, C., and Shropshire, K. J. (2010). Non-native plants reduce abundance, richness, and host specialization in lepidopteran communities. Ecosphere 1, art11. doi: 10.1890/ES10-00032.1

Careau, V., Killen, S. S., and Metcalfe, N. B. (2015). "Adding Fuel to the 'Fire of Life': energy budgets across levels of variation in ectotherms and endotherms," in Integrative Organismal Biology, 219-233.

Cinzano, P., Falchi, F., Elvidge, C. D., and Baugh, K. E. (2000). The artificial night sky brightness mapped from DMSP Operational Linescan System measurements. Mon. Not. R. Astron. Soc. 318, 641-657. doi: 10.1046/j.1365-8711.2000.03562.x

Cresswell, W., Holt, S., Reid, J. M., Whitfield, D. P., Mellanby, R. J., Norton, D., et al. (2004). The energetic costs of egg heating constrain incubation attendance but do not determine daily energy expenditure in the pectoral sandpiper. Behav. Ecol. 15, 498-507. doi: 10.1093/beheco/arh042

Daan, S., Deerenberg, C., and Dijkstra, C. (1996). Increased daily work precipitates natural death in the Kestrel. J. Anim. Ecol. 65, 539. doi: 10.2307/5734

Da Silva, A., de Jong, M., van Grunsven, R. H., Visser, M. E., Kempenaers, B., and Spoelstra, K. (2017). Experimental illumination of a forest: no effects of lights of different colours on the onset of the dawn chorus in songbirds. R. Soc. Open Sci. 4:160638. doi: 10.1098/rsos.160638

Da Silva, A., Samplonius, J. M., Schlicht, E., Valcu, M., and Kempenaers, B. H. A. (2014). Artificial night lighting rather than traffic noise affects the daily timing of dawn and dusk singing in common European songbirds. Behav. Ecol. 25, 1037-1047. doi: 10.1093/beheco/aru103

Davies, T. W., Bennie, J., Inger, R., de Ibarra, N. H., and Gaston, K. J. (2013). Artificial light pollution: are shifting spectral signatures changing the balance of species interactions? Glob. Chang. Biol. 19, 1417-1423. doi: 10.1111/gcb.12166

de Jong, M. (2016). Illuminating a Bird's World: Effects of Artificial Light at Night on Avian Ecology. Wageningen: Wageningen University.

de Jong, M., Jeninga, L., Ouyang, J. Q., van Oers, K., Spoelstra, K., and Visser, M. E. (2016a). Dose-dependent responses of avian daily rhythms to artificial light at night. Physiol. Behav. 155, 172-179. doi: 10.1016/j.physbeh.2015.12.012

de Jong, M., Ouyang, J. Q., Da Silva, A., Van Grunsven, R. H., Kempenaers, B., Visser, M. E., et al. (2015). Effects of nocturnal illumination on life-history decisions and fitness in two wild songbird species. Philos. Trans. R. Soc. Lond. B. Biol. Sci. 370, 1-8. doi: 10.1098/rstb.2014.0128

de Jong, M., Ouyang, J. Q., van Grunsven, R. H. A., Visser, M. E., and Spoelstra, K. (2016b). Do wild great tits avoid exposure to light at night? PLoS ONE 11:e0157357. doi: 10.1371/journal.pone.0157357

Dominoni, D. M. (2015). The effects of light pollution on biological rhythms of birds: an integrated, mechanistic perspective. J. Ornithol. 156, 409. doi: 10.1007/s10336-015-1196-3

Dominoni, D. M., Borniger, J. C., and Nelson, R. J. (2016). Light at night, clocks and health: from humans to wild organisms. Biol. Lett. 12:20160015. doi: 10.1098/rsbl.2016.0015

Dominoni, D. M., Carmona-Wagner, E. O., Hofmann, M., Kranstauber, B., and Partecke, J. (2014). Individual-based measurements of light intensity provide new insights into the effects of artificial light at night on daily rhythms of urbandwelling songbirds. J. Anim. Ecol. 83, 681-692. doi: 10.1111/1365-2656.12150

Dominoni, D., Quetting, M., and Partecke, J. (2013). Artificial light at night advances avian reproductive physiology. Proc. R. Soc. B Biol. Sci. 280:20123017. doi: 10.1098/rspb.2012.3017

Dwyer, R. G., Bearhop, S., Campbell, H. A., and Bryant, D. M. (2013). Shedding light on light: benefits of anthropogenic illumination to a nocturnally foraging shorebird. J. Anim. Ecol. 82, 478-485. doi: 10.1111/1365-2656.12012
Falchi, F., Cinzano, P., Duriscoe, D., Kyba, C. C., Elvidge, C. D., Baugh, K., et al. (2016). The new world atlas of artificial night sky brightness. Sci. Adv. 2:e1600377. doi: 10.1126/sciadv.1600377

Fletcher, Q. E., Selman, C., Boutin, S., McAdam, A. G., Woods, S. B., Seo, A. Y., et al. (2013). Oxidative damage increases with reproductive energy expenditure and is reduced by food-supplementation. Evolution (N. Y). 67, 1527-1536. doi: 10.1111/evo.12014

Gaston, K. J., Bennie, J., Davies, T. W., and Hopkins, J. (2013). The ecological impacts of nighttime light pollution: a mechanistic appraisal. Biol. Rev. 88, 912-927. doi: 10.1111/brv.12036

Gaston, K. J., Davies, T. W., Bennie, J., and Hopkins, J. (2012). REVIEW: reducing the ecological consequences of night-time light pollution: options and developments. J. Appl. Ecol. 49, 1256-1266. doi: 10.1111/j.1365-2664.2012.02212.x

Giordano, M., Costantini, D., and Tschirren, B. (2015). Sex-specific effects of prenatal and postnatal nutritional conditions on the oxidative status of great tit nestlings. Oecologia 177, 123-131. doi: 10.1007/s00442-014-3100-x

Hinsley, S. A., Hill, R. A., Bellamy, P. E., Harrison, N. M., Speakman, J. R., Wilson, A. K., et al. (2008). Effects of structural and functional habitat gaps on breeding woodland birds: working harder for less. Landsc. Ecol. 23, 615-626. doi: 10.1007/s10980-008-9225-8

Hölker, F., Wolter, C., Perkin, E. K., and Tockner, K. (2010). Light pollution as a biodiversity threat. Trends Ecol. Evol. 25, 681-682. doi: 10.1016/j.tree.2010.09.007

Hothorn, T., Bretz, F., and Westfall, P. (2008). Simultaneous inference in general parametric models. Biometrical J. 50, 346-363. doi: 10.1002/bimj.200810425

Hudson, L. N., Isaac, N. J. B., and Reuman, D. C. (2013). The relationship between body mass and field metabolic rate among individual birds and mammals. $J$. Anim. Ecol. 82, 1009-1020. doi: 10.1111/1365-2656.12086

Hunt, D. M., Hankins, M. W., Collin, S. P., and Marshall, N. J. (eds.). (2014). Evolution of Visual and Non-visual Pigments. Boston, MA: Springer.

Isaksson, C., and Andersson, S. (2007). Carotenoid diet and nestling provisioning in urban and rural great tits Parus major. J. Avian Biol. 38, 564-572. doi: 10.1111/j.0908-8857.2007.04030.x

Kempenaers, B., Borgström, P., Loës, P., Schlicht, E., and Valcu, M. (2010). Artificial night lighting affects dawn song, extra-pair siring success, and lay date in songbirds. Curr. Biol. 20, 1735-1739. doi: 10.1016/j.cub.2010. 08.028

Kersten, M., and Piersma, T. (2002). High levels of energy expenditure in shorebirds; metabolic adaptations to an energetically expensive way of life. Ardea 38-90, 175-187. doi: 10.5253/arde.v75.p175

Killen, S. S., Marras, S., Metcalfe, N. B., McKenzie, D. J., and Domenici, P. (2013). Environmental stressors alter relationships between physiology and behaviour. Trends Ecol. Evol. (Amst). 28, 651-658. doi: 10.1016/j.tree.2013.05.005

Kuznetsova, A., Brockhoff, P., and Bojesen, R. (2016). Lmertest: Tests in Linear Mixed Effects Models. R package version 2.0-30. Available online at: https://cran.r-project.org/package=lmerTest

Markwald, R. R., Melanson, E. L., Smith, M. R., Higgins, J., Perreault, L., Eckel, R. H., et al. (2013). Impact of insufficient sleep on total daily energy expenditure, food intake and weight gain. Proc. Natl. Acad. Sci. U.S.A. 110, 5695-5700. doi: $10.1073 /$ pnas.1216951110

Mertens, J. A. L. (1987). The influence of temperature on the energy reserves of female Great Tits during breeding season. Ardea 75, 73-80.

Migaud, H., Cowan, M., Taylor, J., and Ferguson, H. W. (2007). The effect of spectral composition and light intensity on melatonin, stress and retinal damage in post-smolt Atlantic salmon, Salmo salar. Aquaculture 270, 390-404. doi: 10.1016/j.aquaculture.2007.04.064

Mitchell, G. W., Guglielmo, C. G., and Hobson, K. A. (2015). Measurement of whole-body $\mathrm{CO}_{2}$ production in birds using real-time laser-derived measurements of hydrogen $\left(\begin{array}{lll}\delta^{2} & \mathrm{H}\end{array}\right)$ and oxygen $\left(\begin{array}{lll}\delta & 18 & \mathrm{O}\end{array}\right)$ isotope concentrations in water vapor from breath. Physiol. Biochem. Zool. 88, 599-606. doi: $10.1086 / 683013$

Nagy, K. A. (2005). Field metabolic rate and body size. J. Exp. Biol. 208, 1621-1625. doi: $10.1242 /$ jeb. 01553

Ouyang, J. Q., de Jong, M., Hau, M., Visser, M. E., van Grunsven, R. H., Spoelstra, K., et al. (2015). Stressful colours: corticosterone concentrations in a free-living songbird vary with the spectral composition of experimental illumination. Biol. Lett. 11, 13-20. doi: 10.1098/rsbl.2015.0517 
Ouyang, J. Q., de Jong, M., van Grunsven, R. H. A., Matson, K. D., Haussmann, M. F., Meerlo, P., et al. (in press). Restless roosts - light pollution affects behavior, sleep and physiology in a free-living songbird. Glob. Change Biol.

Peirson, S. N., Halford, S., and Foster, R. G. (2009). The evolution of irradiance detection: melanopsin and the non-visual opsins. Philos. Trans. R. Soc. B. 364, 2849-2865. doi: 10.1098/rstb.2009.0050

Perrins, C. M. (1991). Tits and their caterpillar food supply. Ibis (Lond. 1859). 133, 49-54. doi: 10.1111/j.1474-919X.1991.tb07668.x

Pohl, H. (1977). Circadian rhythms of metabolism in cardueline finches as function of light intensity and season. Comp. Biochem. Physiol. 56A, 145-153. doi: 10.1016/0300-9629(77)90176-1

Poot, H., Ens, B. J., De Vries, H., Donners, M. A. H., Wernand, M. R., Marquenie, J. M., et al. (2008). Green light for nocturnally migrating birds. Ecol. Soc. 13, 1-14. doi: 10.5751/es-02720-130247

Raap, T., Casasole, G., Costantini, D., AbdElgawad, H., Asard, H., Pinxten, R., et al. (2016a). Artificial light at night affects body mass but not oxidative status in free-living nestling songbirds: an experimental study. Sci. Rep. 6:35626. doi: $10.1038 /$ srep35626

Raap, T., Casasole, G., Pinxten, R., and Eens, M. (2016b). Early life exposure to artificial light at night affects the physiological condition: an experimental study on the ecophysiology of free-living nestling songbirds. Environ. Pollut. 218, 909-914. doi: 10.1016/j.envpol.2016.08.024

Raap, T., Pinxten, R., and Eens, M. (2015). Light pollution disrupts sleep in free-living animals. Sci. Rep. 5:13557. doi: 10.1038/srep13557

R Development Core Team (2015). R: A Language and Environment for Statistical Computing. Available online at: URL http//www. R-project. Org.

Regular, P. M., Hedd, A., Montevecchi, W. A., Robertson, G. J., Storey, A. E., and Walsh, C. J. (2014). Why timing is everything: energetic costs and reproductive consequences of resource mismatch for a chick-rearing seabird. Ecosphere 5, 1-13. doi: 10.1890/ES14-00182.1

Rich, C., and Longcore, T. (2006). Artificial Night Lighting. Washington, DC: Island Press.

Ricklefs, R. E., Konarzewski, M., and Daan, S. (1996). The relationship between basal metabolic rate and daily energy expenditure in birds and mammals. Am. Nat. 147, 1047-1071. doi: 10.1086/285892

Robert, K. A., Lesku, J. A., Partecke, J., and Chambers, B. (2015). Artificial light at night desynchronizes strictly seasonal reproduction in a wild mammal. Proc. Biol. Sci. 282:20151745. doi: 10.1098/rspb.2015.1745

Rotics, S., Dayan, T., and Kronfeld-Schor, N. (2011). Effect of artificial night lighting on temporally partitioned spiny mice. J. Mammal. 92, 159-168. doi: 10.1644/10-MAMM-A-112.1

Russ, A., Rüger, A., and Klenke, R. (2015). Seize the night: European Blackbirds (Turdus merula) extend their foraging activity under artificial illumination. J. Ornithol. 156, 123-131. doi: 10.1007/s10336-014-1105-1

Sanders, D., Kehoe, R., Tiley, K., Bennie, J., Cruse, D., Davies, T. W., et al. (2015). Artificial nighttime light changes aphid-parasitoid population dynamics. Sci. Rep. 5:15232. doi: 10.1038/srep15232

Santos, C. D., Miranda, A. C., Granadeiro, J. P., Lourenço, P. M., Saraiva, S., and Palmeirim, J. M. (2010). Effects of artificial illumination on the nocturnal foraging of waders. Acta Oecol. 36, 166-172. doi: 10.1016/j.actao.2009.11.008

Selman, C., McLaren, J. S., Collins, A. R., Duthie, G. G., and Speakman, J. R. (2008). The impact of experimentally elevated energy expenditure on oxidative stress and lifespan in the short-tailed field vole Microtus agrestis. Proc. R. Soc. B Biol. Sci. 275, 1907-1916. doi: 10.1098/rspb.2008.0355

Speakman, J. (1997). Doubly Labelled Water: Theory and Practice. London: Chapman \& Hall.

Speakman, J. R., and Selman, C. (2011). The free-radical damage theory: accumulating evidence against a simple link of oxidative stress to ageing and lifespan. Bioessays 33, 255-259. doi: 10.1002/bies.201000132

Speakman, J. R., Selman, C., McLaren, J. S., and Harper, E. J. (2002). Living fast, dying when? The link between aging and energetics. J. Nutr. 132, 1583S-1597S.

Spoelstra, K., van Grunsven, R. H., Donners, M., Gienapp, P., Huigens, M. E., Slaterus, R., et al. (2015). Experimental illumination of natural habitat-an experimental set-up to assess the direct and indirect ecological consequences of artificial light of different spectral composition. Philos. Trans. R. Soc. B Biol. Sci. 370:20140129. doi: 10.1098/rstb.2014.0129
Spoelstra, K., and Visser, M. E. (2013). "The impact of artificial light on avian ecology," in Avian Urban Ecology, eds D. Gil and H. Brumm (Oxford: Oxford University Press), 21-28.

Stone, E. L., Jones, G., and Harris, S. (2009). Street lighting disturbs commuting bats. Curr. Biol. 19, 1123-1127. doi: 10.1016/j.cub.2009.05.058

Swaddle, J. P., Francis, C. D., Barber, J. R., Cooper, C. B., Kyba, C. C., Dominoni, D. M., et al. (2015). A framework to assess evolutionary responses to anthropogenic light and sound. Trends Ecol. Evol. 30, 550-560. doi: 10.1016/j.tree.2015.06.009

Tallamy, D. W., and Shropshire, K. J. (2009). Ranking lepidopteran use of native versus introduced plants. Conserv. Biol. 23, 941-947. doi: 10.1111/j.1523-1739.2009.01202.x

Te Marvelde, L., Webber, S. L., Meijer, H. A. J., and Visser, M. E. (2011). Mismatched reproduction is energetically costly for chick feeding female great tits. Funct. Ecol. 25, 1302-1308. doi: 10.1111/j.1365-2435.2011.01889.x

Tinbergen, J. M., and Dietz, M. W. (1994). Parental energy expenditure during brood rearing in the Great Tit (Parus major) in relation to body mass, temperature, food availability and clutch size. Funct. Ecol. 8, 563-572. doi: $10.2307 / 2389916$

Tinbergen, J. M., and Verhulst, S. (2000). A fixed energetic ceiling to parental effort in the great tit? J. Anim. Ecol. 69, 323-334. doi: 10.1046/j.1365-2656.2000.00395.x

Titulaer, M., Spoelstra, K., Lange, C. Y., and Visser, M. E. (2012). Activity patterns during food provisioning are affected by artificial light in free living Great Tits (Parus major). PLoS ONE 7:e37377. doi: 10.1371/journal.pone.0037377

van Langevelde, F., Ettema, J. A., Donners, M., WallisDeVries, M. F., and Groenendijk, D. (2011). Effect of spectral composition of artificial light on the attraction of moths. Biol. Conserv. 144, 2274-2281. doi: 10.1016/j.biocon.2011.06.004

Vehrencamp, S. L., Bradbury, J. W., and Gibson, R. M. (1989). The energetic cost of display in male sage grouse. Anim. Behav. 38, 885-896. doi: 10.1016/S0003-3472(89)80120-4

Verhulst, S., and Tinbergen, J. M. (1997). Clutch size and parental effort in the Great Tit Parus major. Ardea 85, 111-126.

Visser, M. E., Holleman, L. J., and Gienapp, P. (2006). Shifts in caterpillar biomass phenology due to climate change and its impact on the breeding biology of an insectivorous bird. Oecologia 147, 164-172. doi: 10.1007/s00442-005-0299-6

Weimerskirch, H., Shaffer, S. A., Mabille, G., Martin, J., Boutard, O., and Rouanet, J. L. (2002). Heart rate and energy expenditure of incubating wandering albatrosses: basal levels, natural variation, and the effects of human disturbance. J. Exp. Biol. 205, 475-483.

Welcker, J., Harding, A. M. A., Kitaysky, A. S., Speakman, J. R., and Gabrielsen, G. W. (2009). Daily energy expenditure increases in response to low nutritional stress in an Arctic-breeding seabird with no effect on mortality. Funct. Ecol. 23, 1081-1090. doi: 10.1111/j.1365-2435.2009.01585.x

Wiersma, P., Muñoz-Garcia, A., Walker, A., and Williams, J. B. (2007). Tropical birds have a slow pace of life. Proc. Natl. Acad. Sci. U.S.A. 104, 9340-9345. doi: 10.1073/pnas.0702212104

Williams, T. D. (2012). Physiological Adaptations for Breeding in Birds. Princeton: Princeton University Press.

Conflict of Interest Statement: The authors declare that the research was conducted in the absence of any commercial or financial relationships that could be construed as a potential conflict of interest.

The reviewer AN and handling Editor declared their shared affiliation, and the handling Editor states that the process nevertheless met the standards of a fair and objective review.

Copyright (c) 2017 Welbers, van Dis, Kolvoort, Ouyang, Visser, Spoelstra and Dominoni. This is an open-access article distributed under the terms of the Creative Commons Attribution License (CC BY). The use, distribution or reproduction in other forums is permitted, provided the original author(s) or licensor are credited and that the original publication in this journal is cited, in accordance with accepted academic practice. No use, distribution or reproduction is permitted which does not comply with these terms. 